\title{
O uso do custeio baseado EM atividades no gerenciamento de custos: pesquisa-ação em uma agência bancária
}

\author{
Elizabete Ribeiro Sanches da Silva, M.Sc. \\ Doutoranda do Programa de Pós Graduação em Eng. de Produção - UFSC - Florianópolis/SC \\ Professora da Faculdade de Ciências Sociais e Aplicadas do Sul de Minas - FACESM - Itajubá/MG \\ beribeiro@uol.com.br \\ Antonio Cezar Bornia, Dr. \\ Professor do Programa de Pós Graduação em Eng. de Produção - UFSC - Florianópolis/SC \\ cezar@eps.ufsc.br
}

O presente artigo discute a importância de uma metodologia de implantação do Custeio Baseado em Atividades (ABC - Activity Based Costing). Para isso foi feita uma análise de abordagens de diversos autores, utilizando-se do ciclo PDCA (Plan, Do, Check, Action).

As etapas de implantação do $A B C$, propostas por este artigo, foram determinadas com o intuito de apoiar o gerenciamento dos custos e a tomada de decisão numa agência bancária. A metodologia proposta foi avaliada e validada através de uma pesquisa-ação em uma agência bancária, constituindo o objetivo principal do artigo.

A metodologia proposta soma-se ao modelo de avaliação de desempenho utilizado pela agência, o qual baseia-se em metas e fatores de desempenho. Surge então um novo sistema que agrega informações financeiras e não-financeiras, de grande utilidade para o banco.

Palavras chave: custeio baseado em atividades; metodologia; gestão bancária.

This paper propose a methodology of implantation of Activity Based Costing (ABC). For that it was made an analysis of several authors approaches, through PDCA analysis.

The stages of implantation of $A B C$, proposed by this paper, were made with the purpose of supporting the management of the costs and the decision making in a banking agency. The principal objective of this paper is the validation of the proposed methodology, through its application in banking agency.

The proposed methodology is added to the performance assessment model used by the agency, which is based the targets and factors of the performance. Then, it is given the new system that aggregates the financial and non-financial information.

Keywords: Activity Based Costing; methodology; banking management.

\section{Introdução}

Companhias em muitas partes do setor de serviços estão procurando refinar seus sistemas de custeio. Os bancos, por exemplo, estão investindo em novos sistemas de custo para entender como o custo de seus produtos e serviços individuais diferem (Horngren, 1997).

De acordo com Reis (1998), as empresas de serviços e os Bancos estão sofrendo, em todo o mundo, verdadeiros abalos, motivados pela globalização, pela rapidez da evolução da tecnologia e pela necessidade de, constantemente, estarem inovando a oferta de produtos.
Conforme Mabberley (1998), gerentes de todos os níveis das Instituições Financeiras agora percebem a importância de controlar seus custos para melhorar a lucratividade global. Há muitos desafios no gerenciamento do complexo ambiente de qualquer instituição financeira.

As vantagens competitivas com a implantação do método de custeio $A B C$ estendem-se desde o gerenciamento financeiro até o coração da organização. Segundo Geishecker (1997), existem 3 benefícios básicos:

- ajudar a organização a obter mais e melhores informações sobre seus processos e atividades, o que por sua vez permite que a eficiência das operações seja continuamente aumentada; 
- racionalizar e otimizar a alocação de pessoal, capital e outros ativos;

- agilizar a 'nova’ organização baseada em atividades e voltá-la para o mercado, o que resulta em uma posição competitiva mais forte diante dos concorrentes.

Neste contexto de transformações, este artigo discute a importância do gerenciamento dos sistemas de custos de uma agência bancária, em especial o $A B C$, podendo ser utilizado como ferramenta de apoio às tomadas de decisões. Para isso estabeleceu-se uma metodologia de implantação do $A B C$.

O artigo é dividido em 3 partes: a primeira parte consta da descrição de diversos autores sobre metodologias de implantação do $A B C$; a segunda parte consta da metodologia de implantação de $A B C$, proposta por este artigo; e a terceira parte consta da validação da metodologia em uma agência bancária. É importante ressaltar que todos os dados de custos da referida agência, apresentados neste artigo, são fictícios.

\section{Por que implantar sistemas $A B C$}

Kaplan (1999) afirma que: “O $A B C$ é uma técnica que pode ser aplicada às empresas prestadoras de serviços - na verdade, estas enfrentam problemas ainda mais difíceis que os das companhias industriais, pois basicamente todas as suas despesas são indiretas. Isso ocorre, por exemplo, com bancos, companhias de seguro, transportadoras, que só agora podem ter uma visão mais clara da rentabilidade de seus diversos produtos e serviços”.

Reforça Drucker (1999) que “O custeio baseado na atividade não só disponibiliza controles melhores de custo, mas crescentemente, também disponibiliza controles de resultados. É provável que seu maior impacto esteja em serviços”.

Cita Brimson (1999) que o custeio baseado na atividade "é um processo de melhoria no feedback de resultados atuais contra o custo planejado para iniciar ação corretiva onde é solicitado”.

Na visão de Mabberley (1998), o ABC pode ser usado em instituições financeiras como base para uma variedade de ferramentas de informação que ajudarão gerentes seniores no gerenciamento da base de custo, como pode também ser usado como base para a Gestão Baseada em Atividades (ABM - Activity Based Management), também como um sistema de orçamento substituto, como um componente central de um sistema de gerenciamento de desempenho ou também como a base para a iniciativa para redução de custo isolada.
$\mathrm{O} A B C$ poderá trazer grandes benefícios às tomadas de decisões que são exigidas dos bancos no atual contexto econômico. Pois além de ser um ambiente propício para sua implementação, o ABC poderá ser utilizado como ferramenta poderosa para alavancar as oportunidades e minimizar os riscos, no que se refere aos custos (Silva, 1998).

\section{Abordagens de implantação do $A B C$}

Qualquer metodologia de implantação de $A B C$ deve ser adaptada às necessidades da empresa que estiver em estudo e aos objetivos de sua implantação. As etapas de implantação precisam ser executadas com cuidado para atender aos objetivos finais.

Neste item são abordadas algumas metodologias de implantação de $A B C$.

Player et al. (1997) descrevem uma metodologia apresentada na Figura 1 que requer oito passos.

\begin{tabular}{|c|l|}
\hline Passo & Tarefa \\
\hline 1 & Definir o escopo do projeto. \\
\hline 2 & Identificar atividades, recursos e geradores. \\
\hline 3 & Elaborar o esquema de custo. \\
\hline 4 & Coletar dados. \\
\hline 5 & Elaborar o modelo de custo. \\
\hline 6 & Validar o modelo de custo. \\
\hline 7 & Interpretar novas informações de custo. \\
\hline 8 & Realizar simulação “what if”. \\
\hline Figura 1 - Metodologia de Player et al. para implantação do $A B C$ \\
$\quad$ Fonte: Player et al. (1997)
\end{tabular}

Segundo Boisvert (1999), a concepção de um sistema de contabilidade por atividades (ou $A B C$ ) corresponde a uma série de etapas cuja ordem de execução difere de acordo com quem concebe o sistema. Além disso, a elaboração da contabilidade por atividades geralmente se inclui no contexto mais amplo da concepção de um sistema de gestão (planejamento e controle) dos custos empresariais. Para ele, esses são os passos essenciais para implantação de $A B C$, conforme apresentado na Figura 2.

Compton (1996) apresenta oito etapas necessárias para implantação de $A B C$, conforme a Figura 3.

Sharmam (1993) apresenta um processo de implantação, em nove etapas, conforme a Figura 4.

Bharara e Lee (1996) apresentam uma metodologia, conforme a Figura 5. 
Produto \& Produção, vol. 6, n. 2, p. 40-57, jun. 2002

\begin{tabular}{|l|l|}
\hline Etapa 1 & Ações \\
\hline $\begin{array}{l}\text { Definição e mensuração das } \\
\text { atividades da empresa }\end{array}$ & $\begin{array}{l}\text { - Descrever as atividades da empresa } \\
\text { - Identificar os recursos às atividades } \\
\text { - Definir os centros de reagrupamento }\end{array}$ \\
\hline Etapa 2 & Ações \\
\hline $\begin{array}{l}\text { Definição e mensuração dos } \\
\text { objetos de custo }\end{array}$ & $\begin{array}{l}\text { - Elaborar uma listagem dos objetos de custo } \\
\text { - Definir os atributos (direcionadores de custo) } \\
\text { - Identificar as atividades aos objetos de custo }\end{array}$ \\
\hline
\end{tabular}

Figura 2 - Metodologia de Boisvert para implantação do $A B C$

Fonte: Boisvert (1999)

\begin{tabular}{|l|}
\hline Etapas \\
\hline 1. Obter apoio e compromisso da administração e dos usuários para com o ABC. \\
\hline 2. Estabelecer uma meta para o projeto. \\
\hline $\begin{array}{l}\text { 3. Organizar uma equipe de administração do projeto, embasar as análises na visão horizontal } \\
\text { e vertical da empresa associadas, e definir um líder para o projeto, que tenha prévio } \\
\text { conhecimento de ABC. }\end{array}$ \\
\hline 4. Planejar o projeto, definindo as tarefas necessárias para executá-lo. \\
\hline 5. Treinar administração, implementadores e usuários. \\
\hline 6. Coletar informações para definir as atividades desempenhadas na empresa. \\
\hline $\begin{array}{l}\text { 7. Desenvolver um modelo de sistema ABC, com os recursos, atividades, direcionadores de } \\
\text { custos, elementos de custos (o valor de cada recurso que cabe a cada atividade) e objetos de } \\
\text { custo. }\end{array}$ \\
\hline 8. Processar o modelo, efetuando as distribuições de custos. \\
\hline
\end{tabular}

Figura 3 - Metodologia de Compton para implantação do $A B C$

Fonte: Compton (1996)

\begin{tabular}{|c|l|}
\hline Passo & Tarefa \\
\hline 1 & Identificar e avaliar a necessidade do ABC \\
\hline 2 & Treinamento \\
\hline 3 & Definir o escopo do projeto \\
\hline 4 & Identificar atividades e direcionadores \\
\hline 5 & Criar um esquema do fluxo operacional e de custos \\
\hline 6 & Coletar dados \\
\hline 7 & Construir um modelo de software, validá-lo e reconcilia-lo \\
\hline 8 & Interpretar resultados e preparar relatórios gerenciais \\
\hline 9 & Integrar dados coletados e relatórios \\
\hline
\end{tabular}

Figura 4 - Metodologia de Sharman para implantação do $A B C$

Fonte: Sharman (1993)

\begin{tabular}{|c|l|}
\hline Passo & Tarefa \\
\hline 1 & Definir o âmbito e metas do sistema de custeio. \\
\hline 2 & Documentar as atividades. \\
\hline 3 & Gerenciar preocupações comportamentais e organizacionais. \\
\hline 4 & Selecionar a base de custo. \\
\hline 5 & Identificar centros de custos do ABC. \\
\hline 6 & Estabelecer a hierarquia das atividades. \\
\hline 7 & Associar custos com atividades e analisar atividades. \\
\hline 8 & Identificar os produtos da empresa. \\
\hline 9 & Determinar os direcionadores de atividade e as quantidades do direcionador. \\
\hline 10 & Processar o modelo. \\
\hline
\end{tabular}

Figura 5 - Metodologia de Bharara e Lee para implantação do $A B C$

Fonte: Bharara e Lee(1996) 
A seguir, é apresentada outra metodologia de implantação de $A B C$, vista na Figura 6 sugerido por $A B C / A B M$ Tutor (1998), com objetivos de utilização para a Gestão Baseada em Atividades (Activity Based Management - ABM).

\begin{tabular}{|c|c|}
\hline Fase 1 & Ações \\
\hline $\begin{array}{l}\text { 1. Definir objetivos, âmbito do projeto e } \\
\text { objetos de custos. } \\
\text { 2. Nomear dono / líder da equipe. } \\
\text { 3. Treinar empregados envolvidos. } \\
\text { 4. Definir o plano do projeto }\end{array}$ & $\begin{array}{l}\text { - Metas do projeto } \\
\text { - Papéis dos membros da equipe } \\
\text { - Treinar equipe } \\
\text { - Planejar projeto }\end{array}$ \\
\hline Fase 2 & Ações \\
\hline $\begin{array}{l}\text { 1. Definir processos e atividades. } \\
\text { 2. Definir atributos (VA, NVA, desperdícios). } \\
\text { 3. Reconciliar os recursos para o modelo } \\
\text { 4. Definir padrões de consumo de recursos. } \\
\text { 5. Definir padrão de consumo de atividades. } \\
\text { 6. Definir produtos, serviços, clientes } \\
\text { 7. Definir métodos de coleta de dados. } \\
\text { 8. Coletar dados. } \\
\text { 9. Transferir dados para o modelo } \\
\text { 10. Processar alocações } \\
\end{array}$ & $\begin{array}{l}\text { - Mapear processos / fluxo. } \\
\text { - Caracterizar atividades. } \\
\text { - Analisar estrutura de recursos. } \\
\text { - Direcionadores de recursos. } \\
\text { - Direcionadores de atividades. } \\
\text { - Objetos de custos. } \\
\text { - Questionários, storyboard, entrevistas, etc. } \\
\text { - Dados para entrada no modelo. } \\
\text { - Modelo software de ABC. } \\
\text { - Resultados do modelo. }\end{array}$ \\
\hline Fase 3 & Ações \\
\hline $\begin{array}{l}\text { 1. Analisar relatórios. } \\
\text { 2. Modificar modelo? } \\
\text { 3. Processar as alocações. } \\
\text { 4. Análise dos relatórios. } \\
\text { 5. Comunicar resultados. } \\
\text { 6. Definir cost drivers para ABM e medidas } \\
\text { de performance para atividades chave e } \\
\text { benchmarking. } \\
\text { 7. Fixação de metas para melhoria. } \\
\text { 8. Decisão: outro estudo piloto ou fase } 4 . \\
\text { 9. Medição de resultados. }\end{array}$ & $\begin{array}{l}\text { - Revisões do modelo. } \\
\text { - Refinar modelo. } \\
\text { - Processar modelo. } \\
\text { - Listar ações. } \\
\text { - Conscientizar empregados. } \\
\text { - Cost drivers para ABM e medição de } \\
\text { desempenho e resultados para benchmarking. } \\
\text { - Objetivos de melhoria. } \\
\text { - Planejar próximas etapas. } \\
\text { - Resultados alcançados. }\end{array}$ \\
\hline Fase 4 & Ações \\
\hline $\begin{array}{l}\text { 1. Integrar a metodologia ABM na empresa } \\
\text { 2. Orçamento baseado na atividade / previsão. } \\
\text { 3. Análise de competitividade } \\
\text { 4. Integração ao sistema gerencial da empresa. }\end{array}$ & $\begin{array}{l}\text { - Novo orçamento e previsão. } \\
\text { - Se não houver competitividade, quais } \\
\text { mudanças são necessárias(recursos, } \\
\text { atividades, produtos). } \\
\text { - Custo ABC em tempo real. }\end{array}$ \\
\hline
\end{tabular}

Figura 6 - Metodologia de $A B C / A B M$ Tutor para implantação do $A B C$ Fonte: $A B C / A B M$ Tutor (1998)

A metodologia acima descreve a implantação do $A B C$ considerando até o item 5 da terceira fase. Deste ponto até o final do processo, serão consideradas fases para o $A B M$. As etapas do $A B C$ constituem do planejamento do trabalho e organização da equipe e as etapas do $A B M$ constituem de ação, integração e exploração das informações.
Mabberley (1998) coloca sua abordagem de auxílio aos sistemas de informações baseado na atividade, apresentada na Figura 7. A abordagem de desenvolver e implantar um sistema de informação baseado na atividade inclui seis fases com um total de 24 passos: 


\begin{tabular}{|l|l|}
\hline Passo & Tarefas \\
\hline \multirow{4}{*}{ Iniciar o projeto. } & $\begin{array}{l}\text { 1. Definir os objetivos do projeto. } \\
\text { 2. Definir a estrutura do projeto. } \\
\text { 3. Desenvolver o caso do negócio. } \\
\text { 4. Gerar planos de projeto detalhados. }\end{array}$ \\
\hline \multirow{2}{*}{$\begin{array}{l}\text { Definir componentes de } \\
\text { dados. }\end{array}$} & $\begin{array}{l}\text { 1. Definir objetos de custos. } \\
\text { 2. Combinar dicionários de atividade. } \\
\text { 3. Determinar os direcionadores de custo e processos de negócios. } \\
\text { 4. Identificar medidas de atividade. }\end{array}$ \\
\hline Colher os dados. & $\begin{array}{l}\text { 1. Definir especificações de dados detalhadas. } \\
\text { 2. Identificar fontes de dados. } \\
\text { 3. Determinar meios de coleta de dados. } \\
\text { 4. Começar coleta de dados. }\end{array}$ \\
\hline $\begin{array}{l}\text { Desenvolver um sistema de } \\
\text { informação baseado na } \\
\text { atividade. }\end{array}$ & $\begin{array}{l}\text { 1. Definir relatórios informativos. } \\
\text { 2. Selecionar e instalar um software. } \\
\text { 3. Desenvolver dados estáticos e interfaces. } \\
\text { Reunir informação baseada }\end{array}$ \\
\hline na atividade. & $\begin{array}{l}\text { 1. Nomear custos e atividades. } \\
\text { 2. Vincular atividades para objetos de custo. } \\
\text { 3. Calcular contribuição. } \\
\text { 4. Estimar o valor agregado. }\end{array}$ \\
\hline Usar a informação. & $\begin{array}{l}\text { 1. Produzir e apresentar a informação. } \\
\text { 2. Demonstrar benefícios imediatos. } \\
\text { 3. Encorajar ação apropriada. } \\
\text { 4. Assegurar progresso continuado. }\end{array}$ \\
\hline
\end{tabular}

Figura 7 - Passos de um Sistema de Informação Baseado na Atividade Fonte: Mabberley (1998)

\section{Avaliação das abordagens}

Segundo Kaplan e Cooper (1998), o método $A B C$ é desenvolvido com base em uma série de quatro etapas básicas seqüenciais:

1. Desenvolver o dicionário de atividades;

2. Determinar quanto a organização está gastando em cada uma de suas atividades;

3. Identificar produtos, serviços e clientes da organização;

4. Selecionar direcionadores de custo da atividade que associam os custos da atividade aos produtos, serviços e clientes da organização.

Conforme se observou nas abordagens dos diversos autores, as etapas básicas citadas por Kaplan e Cooper (1998) foram respeitadas. No entanto, estas abordagens foram avaliadas utilizando o ciclo PDCA descritos no Quadro 8, a fim de subsidiar a metodologia proposta por este artigo.

Para efeito de avaliação das abordagens descritas, alguns itens considerados como principais são citados e a partir deles é que foi analisado se o autor abordou, ou não, em sua metodologia. As abordagens de implantação do $A B C$ são confrontadas aos critérios de avaliação agrupados conforme o ciclo PDCA (Plan, Do, Check, Action), ou seja, as fases das metodologias de $A B C$ são relacionadas com as fases do PDCA, a fim de identificar os pontos fortes e fracos de cada abordagem com relação ao $P$ (Planejamento), $D$ (Execução), $C$ (Avaliação) e A (Ações de Melhoria). Vale destacar que, o objetivo desta avaliação é estabelecer os pontos de união das diferentes abordagens, subsidiando a proposta de uma nova metodologia.

O relacionamento das etapas do PDCA com as abordagens de implantação do $A B C$, e seu respectivo grau, foi validado com especialista da área de custos. 


\begin{tabular}{|c|c|c|c|c|c|c|c|c|}
\hline $\begin{array}{l}\text { Critérios de } \\
\text { avaliação }\end{array}$ & Etapas & 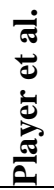 & 突 & 泀 & 䒿 & 苞 & $\stackrel{亡}{ٍ}$ & $\frac{\partial}{\sum^{2}}$ \\
\hline \multirow{8}{*}{ 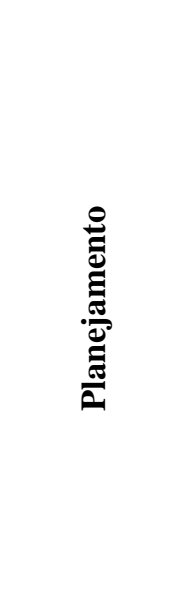 } & Definir o escopo do projeto & $\odot$ & & & $\odot$ & $\odot$ & $\odot$ & $\odot$ \\
\hline & Comprometer a alta gerência & & & $\odot$ & & & & \\
\hline & Avaliar necessidades de implementar $A B C$ & & & & $\odot$ & & & \\
\hline & Capacitar a equipe & & & $\odot$ & $\odot$ & $\mathrm{O}$ & $\odot$ & \\
\hline & $\begin{array}{l}\text { Coletar dados (incluem atividades, direcionadores de } \\
\text { custo de recursos e de atividades, objetos de custo e } \\
\text { recursos disponíveis) }\end{array}$ & $\odot$ & $\odot$ & $\odot$ & $\odot$ & $\odot$ & $\odot$ & $\odot$ \\
\hline & Elaborar o modelo & $\odot$ & $\mathrm{O}$ & $\odot$ & $\odot$ & & $\odot$ & O \\
\hline & $\begin{array}{l}\text { Definir direcionadores para } A B M \text { e medidas de } \\
\text { performance e integração da metodologia } A B M \text { na } \\
\text { empresa. }\end{array}$ & & & & & & $\odot$ & \\
\hline & Integrar ao SIG & & & & $\odot$ & & $\odot$ & $\odot$ \\
\hline \multirow{4}{*}{ 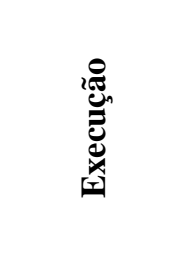 } & Processar o modelo, distribuindo os custos. & $\odot$ & $\odot$ & $\odot$ & $\odot$ & $\odot$ & $\odot$ & $\odot$ \\
\hline & Processar novas informações e interpretar resultados & $\odot$ & & & $\odot$ & & $\odot$ & $\odot$ \\
\hline & $\begin{array}{l}\text { Realizar simulações para subsidiar a proposta de } \\
\text { melhorias no processo. }\end{array}$ & $\odot$ & & & & & & $\odot$ \\
\hline & Listar ações para melhoria dos processos & & & & & & $\odot$ & $\odot$ \\
\hline \multirow{2}{*}{ 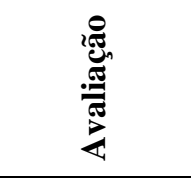 } & $\begin{array}{l}\text { Aferir periodicamente o software, no sentido } \\
\text { operacional. }\end{array}$ & & & & & & & \\
\hline & $\begin{array}{l}\text { Avaliar a metodologia para subsidiar propostas de } \\
\text { melhorias. }\end{array}$ & O & & & & & O & \\
\hline \multirow{2}{*}{ 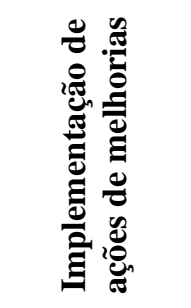 } & $\begin{array}{l}\text { Promover ajustes que garantam a confiabilidade do } \\
\text { software. }\end{array}$ & O & & & & & O & $\odot$ \\
\hline & Implementar ações de aperfeiçoamento na metodologia. & & & & & & $\odot$ & \\
\hline
\end{tabular}

Legenda de relacionamento: - forte: amplamente contemplado; O - médio: parcialmente contemplado.

Figura 8 - Critérios de avaliação de abordagens de implantação do $A B C$

As abordagens analisadas comentam, com mais ênfase, as fases de definição de escopo, coleta de dados, elaboração e processamento do modelo. Todas descrevem, amplamente, as fases de planejamento e execução, conforme demonstrado na Figura 8. No entanto, não se preocupam com a avaliação e implementação de melhorias na metodologia abordada, com exceção de algumas que descrevem, parcialmente, em seu roteiro.

Existe o risco de muitos gestores acharem que basta seguir um roteiro e implantar o novo sistema, para obter bons resultados. Na verdade, nem sempre é o que ocorre. Além da necessidade de cada metodologia ser adaptada à realidade e necessidades da empresa, considera-se necessária também a avaliação e implementação de melhorias na mesma. As condições que justificam uma implantação são dinâmicas, levando às necessidades de aperfeiçoamento contínuo, que podem ser sistematizadas através de avaliações periódicas embutidas no projeto de implantação da metodologia (Silva, 2000).

Considera-se, para efeito de análise neste artigo, que todas as fases devem ser bem claras e exploradas na implantação da metodologia em qualquer organização 


\begin{tabular}{|c|c|}
\hline FASES & TAREFAS \\
\hline \multicolumn{2}{|c|}{ PRIMEIRA FASE: PLANEJAMENTO } \\
\hline INICIAR O PROJETO & $\begin{array}{l}\text { 1. Descrever o escopo e objetivos do projeto. } \\
\text { 2. Identificar e avaliar as necessidades do ABC. } \\
\text { 3. Obter comprometimento da gerência. }\end{array}$ \\
\hline $\begin{array}{l}\text { ELABORAR O PLANO } \\
\text { DE AÇÃO }\end{array}$ & $\begin{array}{l}\text { 1. Definição dos meios de coleta de dados. } \\
\text { 2. Definir atividades. } \\
\text { 3. Definir direcionadores. } \\
\text { 4. Definir objetos de custo } \\
\text { 5. Obter os dados de custo. } \\
\text { 6. Definir o software. } \\
\text { 7. Integrar ao sistema de informações gerenciais. }\end{array}$ \\
\hline \multicolumn{2}{|c|}{ SEGUNDA FASE: EXECUÇÃO } \\
\hline $\begin{array}{l}\text { PROCESSAR E } \\
\text { ANALISAR O PLANO DE } \\
\text { AÇÃO }\end{array}$ & $\begin{array}{l}\text { 1. Processar os dados. } \\
\text { 2. Interpretar resultados. } \\
\text { 3. Apresentar as informações. } \\
\text { 4. Realizar simulações para propostas de melhorias no processo. } \\
\text { 5. Listar ações para melhorias no processo. } \\
\end{array}$ \\
\hline \multicolumn{2}{|c|}{ TERCEIRA FASE: AVALIAÇÃO } \\
\hline $\begin{array}{l}\text { VERIFICAR O } \\
\text { SOFTWARE E A } \\
\text { METODOLOGIA }\end{array}$ & $\begin{array}{l}\text { 1. Aferir periodicamente o software. } \\
\text { 2. Avaliar a metodologia, subsidiando propostas de melhorias. }\end{array}$ \\
\hline \multicolumn{2}{|c|}{ QUARTA FASE: IMPLEMENTAÇÃO DE AÇÕES DE MELHORIA } \\
\hline $\begin{array}{l}\text { IMPLEMENTAR AÇÕES } \\
\text { VISANDO A MELHORIA } \\
\text { DA METODOLOGIA } \\
\end{array}$ & $\begin{array}{l}\text { 1. Promover ajustes que garantam a confiabilidade do software. } \\
\text { 2. Implementar ações de aperfeiçoamento na metodologia. }\end{array}$ \\
\hline
\end{tabular}

Figura 9- Metodologia proposta para implantação do $A B C$

(industrial ou de serviços), tais como: o planejamento, a execução, a avaliação e implementação de ações de melhoria. Baseada nessas premissas é que será elaborada a proposta a seguir. Trata-se de uma nova metodologia, que vai além da implantação; preocupase também com a sua continuidade, através de aferições e avaliações para melhorias futuras, assegurando o seu progresso continuado e seus benefícios.

\section{Proposta de uma metodologia para custeio baseado em atividade}

A metodologia proposta por este artigo agrega todas fases contempladas no ciclo PDCA. As fases 1 e 2 compreendem o PLANEJAMENTO do projeto, a fase 3 refere-se à sua EXECUÇÃO, a fase 4 é a AVALIAÇÃO da metodologia e a fase 5 constitui a implementação de AÇÕES DE MELHORIAS, conforme se identifica na Figura 9.

\section{Pesquisa-ação em uma agência bancária}

Pode-se dizer que o $A B C$ se aplica em qualquer agência bancária. Segundo Kaplan e Cooper (1998):

- na área bancária as despesas indiretas e as de suporte são bastante representativas;
- na área bancária, há uma situação de diversidade de produtos, clientes e processos.

A metodologia proposta para implementação do $A B C$ é avaliada em uma agência bancária.

\subsection{Descrição da agência bancária}

Trata-se de uma agência que tem, em média, 280 clientes por funcionário e a rentabilidade média dos funcionários está 3,44 vezes acima da média da Instituição, sendo assim considerada uma agência modelo para o banco. Seus principais produtos são poupança, cheque especial e fundo de investimentos.

O Banco utiliza o custeio variável, ou seja, considera como custo de seus produtos apenas as despesas identificáveis com os produtos e que variam em função dos volumes transacionados, por exemplo: despesas financeiras, despesas de oportunidades e royalties. As demais despesas são consideradas despesas estruturais da agência - são as despesas administrativas - e estão sob a responsabilidade de cada agência. Este é o grande motivo para que a gerência dê uma atenção especial para este grupo das despesas, pois elas influenciam diretamente o seu resultado e podem, ao mesmo tempo, ser controladas pela agência. Dentre as despesas administrativas, destaca-se a despesa de pessoal, que representa em torno de $90 \%$ do total. 
As atividades desenvolvidas pela organização exigem contato direto com os clientes; esta característica levou a organização a buscar o comprometimento dos funcionários através do uso de um Modelo de Avaliação Profissional, baseado em metas e fatores de desempenho.

Esta preocupação vem ao encontro da afirmação de Kaplan (1997): “É importante que os executivos entendam que não serão superados pelos concorrentes se mudarem e se aperfeiçoarem contínua e mais rapidamente do que eles. Mas convém que se dêem conta de que a fonte de crescimento e aprendizado são os funcionários da empresa - somente graças a ele é possível continuar melhorando as operações”.

A metodologia proposta fornecerá subsídios de análise e controle das atividades operacionais, com seus respectivos custos.

\subsection{Etapas de aplicação do método $A B C$}

\subsubsection{Descrição do escopo e objetivos do projeto}

Apoiar os processos de controle e tomada de decisões por parte do gestor da agência bancária no que se refere ao gerenciamento de custos, utilizando como ferramenta principal o $A B C$.

\subsubsection{Avaliação das necessidades do $A B C$}

Novas ferramentas de gestão fazem-se necessárias, tendo em vista que a agência está expandindo cada vez mais a gama de clientes, em função dos novos produtos que são direcionados às categorias específicas de clientes. Nos últimos três anos observou-se um acréscimo na faixa de $80 \%$.

\subsubsection{Comprometimento da gerência}

O apoio e participação da gerência criou oportunidades para a aplicação da nova metodologia de custeio.

\subsubsection{Meios de coleta de dados}

Observação (leitura e análise) dos documentos utilizados pela agência; entrevista com todos os gerentes a respeito das tarefas desenvolvidas; questionário feito diretamente com todos os funcionários.

\subsubsection{Definição das atividades}

As atividades identificadas seguiram a metodologia do menor para o maior, ou seja: primeiramente, foi feito o mapeamento das tarefas executadas; posteriormente, fez-se o agrupamento dessas tarefas em atividades, ou grupo de tarefas.

As atividades representam uma abordagem resumida de todas as tarefas executadas na agência. Este resumo serviu de base para a realização do dicionário de atividades da agência, conforme a Figura 10.

\begin{tabular}{|l|l|}
\hline ATIVIDADES & \multicolumn{1}{|c|}{ SIGNIFICADO } \\
\hline 1. Administrar pessoal. & $\begin{array}{l}\text { Emitir ordens de serviço para otimizar os recursos humanos através } \\
\text { do acompanhamento dos acordos de equipe (GDP e Distribuição de } \\
\text { metas) e administração de pessoal. Isso permite o equilíbrio das } \\
\text { equipes de forma a não prejudicar o atendimento. }\end{array}$ \\
\hline 2. Visitar os clientes. & Visitar, periodicamente, os clientes. \\
\hline 3. Visitar outras agências e demais órgãos & Harmonização de procedimentos e discussão de diretrizes e metas. \\
\hline 4. Atender aos clientes comuns & $\begin{array}{l}\text { Prestar informações aos clientes na agência e via sistema eletrônico, } \\
\text { contato com cliente para abertura de contas correntes, solicitação e } \\
\text { entrega de documentos, efetuar atualizações cadastrais em conta } \\
\text { corrente, solicitar cartões, efetuar alterações de senha e contra } \\
\text { ordem, exclusão do cliente no Cadastro de emitentes de cheque sem } \\
\text { fundo e efetuar serviços de caixa em geral (pagamento/recebimento, } \\
\text { saques, gravação e liberação de DOC's - Documentos de Crédito, } \\
\text { recebimento e emissão de cobrança sacado, entregar cartão } \\
\text { magnético e talão, processar papéis do atendimento opcional aos } \\
\text { clientes e abastecer de numerários os caixas da agência e postos). }\end{array}$ \\
\hline $\begin{array}{l}\text { 5. Atender aos clientes VIP's } \\
\text { Assessorar o auto-atendimento dos } \\
\text { clientes. }\end{array}$ & $\begin{array}{l}\text { Prestar informações aos clientes VIP's e efetuar serviços de caixa } \\
\text { em geral (pagamento/recebimento, saques, gravação e liberação de } \\
\text { DOC's - Documentos de Crédito, recebimento e emissão de } \\
\text { cobrança sacado, entregar cartão magnético e talão). }\end{array}$ \\
\hline $\begin{array}{l}\text { Atender aos clientes na sala de auto-atendimento e realizar } \\
\text { manutenção das máquinas. }\end{array}$ \\
\hline
\end{tabular}




\begin{tabular}{|c|c|}
\hline ATIVIDADES & SIGNIFICADO \\
\hline $\begin{array}{l}\text { Ler e distribuir comunicação formal e } \\
\text { eletrônica. }\end{array}$ & $\begin{array}{l}\text { Manter atualizada a caixa postal da agência e difundir informativo } \\
\text { interno. }\end{array}$ \\
\hline 8. Cuidar da gestão contábil e financeira. & $\begin{array}{l}\text { Autorizar regularização de defraudações, conferir balancetes, liberar } \\
\text { despesas administrativas, liberar partidas interdepartamentais. }\end{array}$ \\
\hline 9. Cuidar da administração predial. & Gerenciar serviços de manutenção, limpeza e vigilância. \\
\hline 10. Efetuar movimento de tesouraria. & Atividade necessária ao fechamento do saldo diário da agência \\
\hline 11. Executar serviços relativos a câmbio. & Compra e venda dos cheques de viagem e gravação nos sistemas. \\
\hline 12. Vender produtos. & Atividade que visa aumentar a receita da agência \\
\hline 13. Analisar e selecionar clientes da Sala VIP. & $\begin{array}{l}\text { Seleção de clientes, visando a melhoria da rentabilidade do setor e } \\
\text { da própria agência }\end{array}$ \\
\hline $\begin{array}{l}\text { 14. Efetuar empréstimos a Pessoa Física e } \\
\text { Pessoa Jurídica. }\end{array}$ & $\begin{array}{l}\text { Operações com crédito direto ao consumidor, leasing, renegociação } \\
\text { de dívida, desconto de notas promissórias, projeto educação - } \\
\text { microcomputador, etc. }\end{array}$ \\
\hline 15. Vender Seguros. & $\begin{array}{l}\text { Estabelecer contato com clientes para renovação ou contratação de } \\
\text { novo seguro, controle dos vencimentos, gravação de propostas, e } \\
\text { acompanhamento de processos em caso de sinistro. }\end{array}$ \\
\hline 16. Vender planos de previdência. & $\begin{array}{l}\text { Definição do público alvo, contato com o cliente e gravação de } \\
\text { propostas }\end{array}$ \\
\hline $\begin{array}{l}\text { Promover eventos internos referentes a } \\
\text { divulgação de produtos. }\end{array}$ & $\begin{array}{l}\text { Divulgação de produtos para a agência através de cursos de } \\
\text { divulgação e aprendizagem. }\end{array}$ \\
\hline 18. Efetuar serviços referentes às cobranças. & $\begin{array}{l}\text { Acompanhamento das carteiras existentes, cadastramento de novas } \\
\text { carteiras, acolhimento e execução de instruções cedentes }\end{array}$ \\
\hline $\begin{array}{l}\text { Acompanhar e controlar os projetos da } \\
\text { Fundação do Banco }\end{array}$ & Acompanhar e controlar os processos. \\
\hline 20. Organizar arquivos físicos e magnéticos & $\begin{array}{l}\text { Guarda, confecção e expurgo do arquivo geral, dos documentos } \\
\text { contábeis, fichas cadastrais, dossiês de operações, correspondências } \\
\text { e documentos em geral; assim como atualização e transmissão de } \\
\text { todos os sistemas informatizados no Banco. }\end{array}$ \\
\hline 21. Efetuar serviços referentes ao crédito & $\begin{array}{l}\text { Pesquisas cadastrais sobre clientes, estudo e controle das operações } \\
\text { de crédito, controle do limite de crédito e atualização cadastral de } \\
\text { pessoa jurídica, controle e liberação dos contratos de CDC e de } \\
\text { convênios, confecção de contratos de crédito. }\end{array}$ \\
\hline 22. Controlar os recursos materiais da agência & Inventários semestrais, manutenção dos equipamentos e compras. \\
\hline $\begin{array}{l}\text { 23. Efetuar serviços referentes à contabilidade } \\
\text { da agência }\end{array}$ & $\begin{array}{l}\text { Controle, conferência e conciliação contábil, liberação de partidas, } \\
\text { transferência de contas transitórias, controle de orçamento e } \\
\text { despesas administrativas e dos processo de defraudação, confecção } \\
\text { de chaves de segurança para ordens de pagamento e liberação de } \\
\text { ordens bancárias do Tesouro. }\end{array}$ \\
\hline 24. Efetuar serviços de malote da agência & $\begin{array}{l}\text { Serviços de expedição, recepção e distribuição de documentos e } \\
\text { preparação de documentos para microfilmagem. }\end{array}$ \\
\hline 25. Efetuar serviços de compensação. & $\begin{array}{l}\text { Decisão sobre devolução de cheques, preparação da devolução e } \\
\text { regularização da conta transitória de compensação. }\end{array}$ \\
\hline 26. Cuidar dos serviços de apoio à agência. & $\begin{array}{l}\text { Distribuir tarefas, reuniões, despachos diversos, controle de } \\
\text { inadimplências e acompanhamento de metas. }\end{array}$ \\
\hline $\begin{array}{l}\text { 27. Atender as tarefas do Sistema Gerencial } \\
\text { de Vendas }\end{array}$ & $\begin{array}{l}\text { Busca pelo aumento dos negócios e da rentabilidade do } \\
\text { conglomerado. }\end{array}$ \\
\hline
\end{tabular}

Figura 10 - Dicionário de atividades da agência

Este dicionário foi distribuído aos funcionários para preenchimento do tempo gasto em cada atividade. Foram consultados 39 funcionários (99\% do total no mês analisado).

Estas atividades foram classificadas, numa segunda etapa, em atividades-meios, de apoio e fins, conforme se observa na Figura 11. As atividades-meios são consideradas básicas para a concretização dos objetos de custos. As atividades de apoio constituem todas aquelas que servem de suporte ao funcionamento de toda a agência não tendo ligação direta ou específica com um único objeto de custos mas sim com todos os objetos. Por este motivo, estas foram analisadas separadamente, sem que se fizesse seu rastreamento aos objetos de custos. As atividades-fins foram consideradas como diretas aos produtos; como o produto não é o enfoque deste trabalho, estas atividades também são analisadas isoladamente pela agência. 


\subsubsection{Definição dos objetos de custo}

Esta é uma etapa complexa dentro de uma agência bancária, em função dos inúmeros produtos com que ela trabalha e dos diversos processos que um único produto exige. Foi constatado que, para a gestão da agência analisada, o foco principal não é a gestão do processo por produto, mas sim o seu processo global, sendo que a mão de obra é multifuncional e atende a todos os produtos. Foi desenhado um fluxograma dos principais processos da agência (Figura 12), baseando-se em quatro processos básicos: visitar clientes, atender aos clientes comuns, assessorar o auto atendimento dos clientes e atender aos clientes VIP's, os quais foram considerados como objetos de custo conforme a Figura 11.

Da interação das atividades-meios, atividades-fins e atividades de apoio é que surgiu então o fluxograma do processo geral da agência bancária, conforme mostra a Figura 12.

\subsubsection{Dados de custo}

Os itens de custos são assim divididos:

- Despesa Financeira de Captação, despesa de Oportunidade, Custos Variáveis e Serviços internos: representam a parte variável dos custos da agência e estão diretamente relacionados aos produtos

- Despesas Administrativas: representam a parte fixa dos custos da agência, as quais serão utilizadas como recursos no processamento dos dados e rastreamento às atividades, conforme colocados na Tabela 1. Vale destacar que a relação da despesa de pessoal com o custo fixo total é de $86 \%$, para o mês analisado.

\begin{tabular}{|c|c|}
\hline Objetos de custos & Atividades-meios relacionadas \\
\hline Visitas aos clientes & $\begin{array}{l}\text { Administrar pessoal. } \\
\text { Ler e distribuir comunicação formal e eletrônica. } \\
\text { Atender as tarefas do Sistema Gerencial de Vendas. } \\
\text { Promover eventos internos ref. divulgação de produtos. } \\
\text { Efetuar serviços ref. ao crédito. }\end{array}$ \\
\hline $\begin{array}{l}\text { Atendimento de clientes } \\
\text { comuns }\end{array}$ & $\begin{array}{l}\text { Administrar pessoal. } \\
\text { Ler e distribuir comunicação formal e eletrônica. } \\
\text { Promover eventos internos ref. divulgação de produtos. } \\
\text { Efetuar serviços ref. ao crédito. } \\
\text { Organizar arquivos físicos e magnéticos. } \\
\text { Cuidar dos serviços de apoio à Agência. } \\
\text { Efetuar serviços de compensação. } \\
\text { Efetuar serviços de malote da agência. } \\
\text { Visitar outras agências e demais órgãos. }\end{array}$ \\
\hline Atendimento de clientes VIP & $\begin{array}{l}\text { Administrar pessoal. } \\
\text { Ler e distribuir comunicação formal e eletrônica. } \\
\text { Promover eventos internos ref. divulgação de produtos. } \\
\text { Efetuar serviços ref. ao crédito. } \\
\text { Organizar arquivos físicos e magnéticos. } \\
\text { Cuidar dos serviços de apoio à Agência. } \\
\text { Efetuar serviços de compensação. } \\
\text { Efetuar serviços de malote da agência. } \\
\text { Visitar outras agências e demais órgãos. } \\
\text { Acompanhar e controlar os projetos da Fundação do Banco. } \\
\text { Analisar e selecionar clientes da Sala VIP. }\end{array}$ \\
\hline $\begin{array}{l}\text { Assessoria no auto- } \\
\text { atendimento dos clientes }\end{array}$ & $\begin{array}{l}\text { Administrar pessoal. } \\
\text { Ler e distribuir comunicação formal e eletrônica. } \\
\text { Promover eventos internos ref. divulgação de produtos. } \\
\text { Cuidar dos serviços de apoio à Agência. }\end{array}$ \\
\hline
\end{tabular}


Figura 12 - Fluxograma do processo geral da agência bancária Tabela 1 - Custo Fixo Total da Agência (em R\$)

\begin{tabular}{lr}
\hline Relação dos custos fixos & Valor (R\$) \\
\hline Despesa de pessoal & 3.421 \\
Materiais & 38 \\
Segurança & 82 \\
Processamento de dados & 45 \\
Telefone & 120 \\
Água/luz & 99 \\
Depreciação & 80 \\
Amortização & 57 \\
Despesa com móveis e utensílios & 5 \\
Contribuições e doações & 8 \\
Reprodução de documentos & 5 \\
Seguros bens e serviços & 68 \\
Outras despesas administrativas & 3.993 \\
\hline Total
\end{tabular}

\subsubsection{Direcionadores}

Os direcionadores pode ser assim divididos:

- Direcionadores de recursos: o direcionador escolhido para a despesa de pessoal foi a atribuição de cada funcionário nas suas respectivas atividades, ou seja, o tempo. A Tabela 2 exemplifica a alocação dos tempos de três funcionários às atividades.
O mesmo procedimento foi feito com as demais despesas estruturais, dada sua baixa representatividade no total das despesas administrativas. A Tabela 3 exemplifica a proporção (em relação às horas totais da agência) das horas trabalhadas em três setores que será utilizada como índice para direcionador de recurso. Estão exemplificados os setores mais representativos em termos de concentração de atividades, no total de 59\% das horas trabalhadas em toda a agência. 
Tabela 2 - Exemplo dos direcionadores de recursos de pessoal (em horas)

\begin{tabular}{|l|c|c|c|}
\cline { 2 - 4 } \multicolumn{1}{c|}{} & \multicolumn{3}{c|}{ FUNCIONÁRIOS: } \\
\hline ATIVIDADES: & 1 & 2 & 3 \\
\hline Administrar pessoal & 1,20 & 1,20 & - \\
\hline Visitar Clientes & 1,80 & 1,20 & 4,80 \\
\hline Visitar outras agências e demais órgãos & 0,60 & - & - \\
\hline Atender aos clientes comuns & - & 1,20 & - \\
\hline Ler e distribuir comunicação formal e eletrônica & 1,20 & 1,50 & 1,20 \\
\hline Cuidar da gestão contábil e financeira & 1,20 & 0,30 & - \\
\hline Cuidar da administração predial & - & 0,60 & - \\
\hline TEMPO TOTAL DE TRABLAHO & 6,00 & 6,00 & 6,00 \\
\hline
\end{tabular}

Vale destacar que esta metodologia de implantação deve ser analisada cuidadosamente, sob o ponto de vista de direcionadores, se aplicada a outras organizações. No caso estudado, o direcionador tempo foi suficiente para rastrear todos os recursos às atividades. Isso não significa que a análise profunda dos direcionadores não seja importante. Cada item de custo, ou grupo de custo, poderia ter um direcionador específico, conforme todas as aplicações de $A B C$ demonstram. No entanto, aqui não se apresentam diversos direcionadores simplesmente porque o caso não necessitou e concluiu-se que seria inviável tal trabalho.

- Direcionadores de atividades: para cada objeto de custo foi atribuído um percentual de tempo das atividades. A Tabela 4 mostra o percentual de consumo das atividades-meios pelos objetos de custos determinados.

Convém destacar que, os índices utilizados como direcionadores dos recursos e das atividades foram determinados juntamente com os funcionários e respectivos gerentes de cada área e, posteriormente, avaliados com o gerente geral da agência.

\subsubsection{Software}

Foi elaborada uma planilha eletrônica para processamento dos dados coletados, a fim de demonstrar os benefícios provenientes da nova sistemática e incorporar aos sistemas de gerenciamento da agência.

\subsubsection{Incorporação ao sistema de informações da agência}

Todos os resultados deste novo sistema foram incorporados ao sistema de informações utilizado, no sentido de contribuir para a análise gerencial, haja vista seu novo enfoque no nível de processo.

\subsubsection{Processamento dos dados}

Realizou-se em todos os setores da agência o devido rastreamento dos custos conforme a realização de suas atividades.
O somatório do custo de pessoal por atividades de cada funcionário é exemplificado na Tabela 5.

O somatório dos demais custos por atividades é exemplificado na Tabela 6.

Após o rastreamento de todos os custos da agência, baseados nas atividades realizadas, é possível calcular o custo total de cada atividade, conforme mostra a Tabela 7.

O total de custos rastreados por atividades ( $\mathrm{R} \$$ $3.948,42)$ refere-se ao somatório das despesas de pessoal (86\% do total) e outras despesas estruturais (14\%). Ambas foram rastreadas às atividades utilizando-se o direcionador "tempo" ou horas.

Dentre todas as atividades destacam-se: Atender aos clientes comuns e Vender produtos, as quais representam juntas $43 \%$ do custo total da agência. Cabe ao gestor da agência analisar se a valoração destas atividades está coerente com a sua performance financeira, ou seja: se o resultado gerado pelas pessoas que atuam diretamente com estas atividades justifica o seu respectivo custo.

O próximo passo é o cálculo dos objetos de custos, o qual é colocado na Tabela 8 .

As atividades consideradas como Atividades-fins e Atividades de apoio foram destacadas numa planilha separada para fins de análise, já que não foram rastreadas aos objetos de custo, conforme se vê na Tabela 9.

\subsubsection{Interpretação dos resultados}

Pode-se considerar que a interpretação de resultados acontece em dois momentos:

- Quando do custeio das atividades: muitas observações e conclusões, que antes eram impossíveis de se ver com os relatórios existentes, agora já se faz presente, como por exemplo: qual o setor que gera 
Tabela 3 - Exemplo de direcionadores dos demais recursos (em \%)

\begin{tabular}{|c|c|c|c|}
\hline \multirow[b]{2}{*}{ ATIVIDADES: } & \multicolumn{3}{|c|}{ SETORES: } \\
\hline & $\begin{array}{l}\text { Gerência de } \\
\text { atendimento }\end{array}$ & $\begin{array}{l}\text { Gerência de } \\
\text { Bateria/VIP }\end{array}$ & $\begin{array}{c}\text { Gerência } \\
\text { dePessoa } \\
\text { Jurídica/seguros }\end{array}$ \\
\hline 1 Atender aos clientes comuns & 0,06 & 0,19 & 0,03 \\
\hline 2 Atender aos clientes VIP & - & 0,03 & - \\
\hline 3 Ler e distribuir comunicação formal e eletrônica. & 0,01 & - & 0,01 \\
\hline 4 Efetuar movimento de tesouraria. & - & 0,01 & - \\
\hline 5 Executar serviços relativos a câmbio. & 0,01 & 0,02 & - \\
\hline 6 Vender produtos e serviços. & 0,03 & 0,07 & 0,01 \\
\hline 7 Efetuar empréstimos a PF e PJ. & 0,01 & - & 0,01 \\
\hline 8 Vender seguros. & 0,02 & - & 0,03 \\
\hline 9 Vender planos de previdência. & 0,01 & - & - \\
\hline 10 Organizar arquivos físicos e magnéticos & 0,01 & - & - \\
\hline 11 Efetuar serviços referentes ao crédito & 0,01 & - & 0,01 \\
\hline PERCENTUAL DE HORAS DE TRABALHO NO SETOR & $17 \%$ & $32 \%$ & $10 \%$ \\
\hline
\end{tabular}

Tabela 4 - Direcionadores das atividades aos objetos de custos

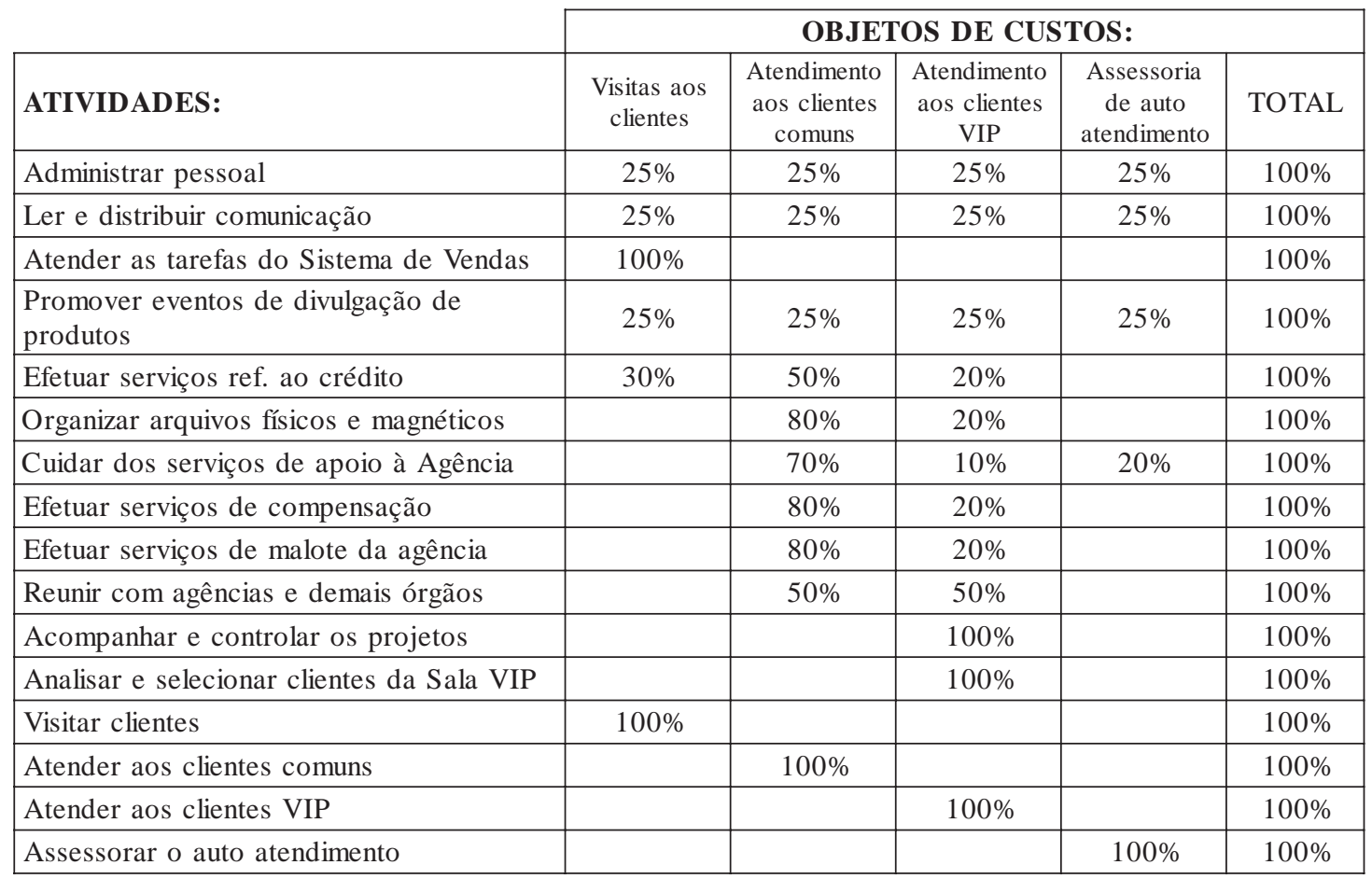

Tabela 5 - Exemplo do cálculo do custo de pessoal por atividades (em R\$)

\begin{tabular}{|l|c|c|c|}
\multicolumn{1}{c}{ ATIVIDADES: } & \multicolumn{2}{c|}{ FUNCIONÁRIOS: } \\
\cline { 2 - 4 } \multicolumn{1}{c|}{} & $\mathbf{1}$ & $\mathbf{2}$ & $\mathbf{3}$ \\
\hline Administrar pessoal & 46,47 & 32,28 & 0 \\
\hline Visitar Clientes & 69,71 & 32,28 & 93,63 \\
\hline Visitar outras agências e demais órgãos & 23,24 & 0 & 0 \\
\hline Atender aos clientes comuns & 0 & 32,28 & 0 \\
\hline Ler e distribuir comunicação formal e eletrônica & 46,47 & 40,35 & 11,70 \\
\hline Cuidar da gestão contábil e financeira & 46,47 & 8,07 & 0 \\
\hline Cuidar da administração predial & 0 & 16,14 & 0 \\
\hline Atender as tarefas do Sistema Gerencial de Vendas & 0 & 0 & 11,70 \\
\hline CUSTO DE PESSOAL POR FUNCIONÁRIO & 232,35 & 161,40 & 117,03 \\
\hline
\end{tabular}


Tabela 6 - Exemplo do cálculo dos demais custos por atividades (em R\$)

\begin{tabular}{|c|c|c|c|}
\hline \multirow[b]{2}{*}{ ATIVIDADES: } & \multicolumn{3}{|c|}{ SETORES: } \\
\hline & $\begin{array}{l}\text { Gerência de } \\
\text { atendimento }\end{array}$ & $\begin{array}{l}\text { Gerência de } \\
\text { Bateria/VIP }\end{array}$ & $\begin{array}{l}\text { Ger. de Pessoa } \\
\text { Jurídica/seguros }\end{array}$ \\
\hline Administrar pessoal & 5,33 & 1,33 & 2,67 \\
\hline Visitar outras agências e demais orgãos & - & - & - \\
\hline Atender aos clientes comuns & 33,58 & 109,27 & 17,59 \\
\hline Atender aos clientes VIP & - & 19,99 & - \\
\hline Ler e distribuir comunicação formal eletrônica & 4,80 & 1,33 & 5,20 \\
\hline Cuidar da gestão contábil e financeira & 0,13 & - & - \\
\hline Cuidar da administração predial & 0,67 & - & - \\
\hline Efetuar movimento de tesouraria & - & 4,00 & - \\
\hline Executar serviços relativos a câmbio & 4,66 & 9,33 & - \\
\hline Vender produtos e serviços, orientando para investimentos & 15,99 & 42,64 & 2,67 \\
\hline Analisar e selecionar clientes da Sala VIP & 2,67 & 6,66 & 0,13 \\
\hline Efetuar empréstimos a Pessoa Física e Pessoa Jurídica & 6,93 & - & 8,00 \\
\hline Vender seguros & 12,26 & 2,00 & 17,32 \\
\hline Vender planos de previdência & 3,60 & - & 1,33 \\
\hline Promover eventos internos ref. a divulgação de produtos & 0,93 & - & - \\
\hline Efetuar serviços ref. às compras & - & - & 1,73 \\
\hline Acompanhar e controlar os proj. da Fundação do Banco & 0,67 & - & 0,27 \\
\hline Organizar arquivos físicos e magnéticos & 4,26 & 0,67 & 1,33 \\
\hline Efetuar serviços referentes ao crédito & 3,46 & - & 2,67 \\
\hline Controlar os recursos materiais da agência & 1,73 & - & - \\
\hline Efetuar serviços referentes à contabilidade da agência & 0,27 & - & - \\
\hline Efetuar serviços de malote da agência & 0,67 & 0,67 & 1,33 \\
\hline Efetuar serviços de compensação & 2,00 & - & 0,40 \\
\hline Cuidar dos serviços gerais de apoio à Agência & 1,33 & 2,00 & - \\
\hline Atender as tarefas do Sistema Gerencial de Vendas & 0,67 & - & 4,00 \\
\hline TOTAL RASTREADO POR SETOR & 106,60 & 199,88 & 66,63 \\
\hline
\end{tabular}

Tabela 7 - Custo das atividades realizadas na agência bancária (em R\$)

\begin{tabular}{|l|c|c|}
\hline ATIVIDADES & CUSTO (R\$) & $\%$ \\
\hline Administrar pessoal & 149,79 & $4 \%$ \\
\hline Visitar clientes & 212,93 & $5 \%$ \\
\hline Visitar outras agências e demais órgãos & 24,59 & $1 \%$ \\
\hline Atender aos clientes comuns & $1.246,33$ & $32 \%$ \\
\hline Atender aos clientes VIP & 140,57 & $4 \%$ \\
\hline Assessorar o auto-atendimento dos clientes & 303,82 & $8 \%$ \\
\hline Ler e distribuir comunicação formal eletrônica & 187,54 & $5 \%$ \\
\hline Cuidar da gestão contábil e financeira & 86,85 & $2 \%$ \\
\hline Cuidar da administração predial & 48,60 & $1 \%$ \\
\hline Efetuar movimento de tesouraria & 27,99 & $1 \%$ \\
\hline Executar serviços relativos a câmbio & 86,39 & $2 \%$ \\
\hline Vender produtos e serviços, orientando para investimentos & 436,44 & $11 \%$ \\
\hline Analisar e selecionar clientes da Sala VIP & 60,33 & $2 \%$ \\
\hline Efetuar empréstimos a Pessoa Física e Pessoa Jurídica & 116,04 & $3 \%$ \\
\hline Vender seguros & 196,76 & $5 \%$ \\
\hline Vender planos de previdência & 33,02 & $1 \%$ \\
\hline Promover eventos internos ref. divulgação de produtos & 6,62 & $0 \%$ \\
\hline Efetuar serviços ref. às cobranças & 9,90 & $0 \%$ \\
\hline
\end{tabular}


Tabela 7 continuação

\begin{tabular}{|l|c|c|}
\hline Acompanhar e controlar os projetos da Fundação do Banco & 2,71 & $0 \%$ \\
\hline Organizar arquivos físicos e magnéticos & 50,91 & $1 \%$ \\
\hline Efetuar serviços referentes ao crédito & 169,11 & $4 \%$ \\
\hline Controlar os recursos materiais da agência & 58,92 & $1 \%$ \\
\hline Efetuar serviços referentes à contabilidade da agência & 50,61 & $1 \%$ \\
\hline Efetuar serviços de malote da agência & 34,55 & $1 \%$ \\
\hline Efetuar serviços de compensação & 25,12 & $1 \%$ \\
\hline Cuidar dos serviços gerais de apoio à Agência & 130,05 & $3 \%$ \\
\hline Atender as tarefas do Sistema Gerencial de Vendas & 51,95 & $1 \%$ \\
\hline
\end{tabular}

Tabela 8 - Cálculo do custo total dos objetos de custos (em R\$)

\begin{tabular}{|l|c|c|c|c|c|}
\cline { 2 - 5 } \multicolumn{2}{|c|}{} & \multicolumn{5}{c|}{ OBJETOS DE CUSTOS: } \\
\hline ATIVID ADES: & $\begin{array}{c}\text { Visitas aos } \\
\text { clientes }\end{array}$ & $\begin{array}{c}\text { Atendimento } \\
\text { aos clientes } \\
\text { comuns }\end{array}$ & $\begin{array}{c}\text { Atendimento } \\
\text { aos clientes } \\
\text { VIP }\end{array}$ & $\begin{array}{c}\text { Assessoria } \\
\text { de auto } \\
\text { atendimento }\end{array}$ & TOTAL \\
\hline Administrar pessoal & 37,45 & 37,45 & 37,45 & 37,45 & 149,79 \\
\hline Ler e distribuir comunicação & 46,88 & 46,88 & 46,88 & 46,88 & 187,54 \\
\hline Atender as tarefas do Sistema Gerencial de Vendas & 51,95 & - & - & - & 51,95 \\
\hline Promover eventos internos ref. divulgação de produtos & 1,66 & 1,66 & 1,66 & 1,66 & 6,62 \\
\hline Efetuar serviços ref. ao crédito & 50,73 & 84,56 & 33,82 & - & 169,11 \\
\hline Organizar arquivos físicos e magnéticos & - & 40,73 & 10,18 & - & 50,91 \\
\hline Cuidar dos serviços de apoio à Agência & - & 91,04 & 13,01 & 26,01 & 130,05 \\
\hline Efetuar serviços de compensação & - & 20,10 & 5,02 & - & 25,12 \\
\hline Efetuar serviços de malote da agência & - & 27,64 & 6,91 & - & 34,55 \\
\hline Reunir com agências e demais órgãos & - & 12,28 & 12,28 & - & 24,57 \\
\hline Acompanhar e controlar os projeto. & - & - & 2,71 & - & 2,71 \\
\hline Analisar e selecionar clientes da Sala VIP & - & - & 60,33 & - & 60,33 \\
\hline Visitar clientes & 212,93 & - & - & - & 212,93 \\
\hline Atender aos clientes comuns & - & $1.246,33$ & - & & $1.246,33$ \\
\hline Atender aos clientes VIP & - & - & 140,57 & - & 140,57 \\
\hline Assessorar o auto atendimento & - & - & - & 303,82 & 303,82 \\
\hline TOTAL ALOCADO AOS OBJETOS DE CUSTO & $\mathbf{4 0 1 , 6 1}$ & $\mathbf{1 . 6 0 8 , 6 6}$ & $\mathbf{3 7 0 , 8 2}$ & $\mathbf{4 1 5 , 8 2}$ & $\mathbf{2 . 7 9 6 , 9 0}$ \\
\hline
\end{tabular}

maior custo; qual a atividade que custa mais à agência; em que atividades os funcionários concentram maior parte do seu tempo; qual a alocação ótima de pessoal.

- Quando do custeio dos objetos de custos: o sistema oferece outros benefícios, como por exemplo: permite ao gerente monitorar o processo da agência e saber qual deles necessita de mais atenção; mostra como importante ferramenta de comunicação e de controle entre os funcionários.

\subsubsection{Apresentação das informações}

Todas as informações geradas pelo sistema devem ser incorporadas ao atual modelo de avaliação de desem- penho e também são distribuídas aos demais gerentes da agência. Compete a estes últimos a divulgação das informações aos seus funcionários, uma vez que a grande parte da origem dos custos encontra-se no nível operacional. Esta nova visão de custos proporciona aos funcionários, de modo geral, um melhor engajamento no sentido de melhorar sua performance, de forma a compensar o custo gerado pelo seu trabalho ou seu setor.

\subsubsection{Realizar simulações para propostas de melhorias no processo}

Todos os variáveis de entrada do sistema, como, por exemplo, a relação das atividades setoriais, a alocação do pessoal em cada atividade, os números de funcio- 
Tabela 9 - Cálculo do custo das Atividades Fins e de Apoio (em R\$)

ATIVIDADES DE APOIO:

\begin{tabular}{|l|r|}
\hline Cuidar da administração predial & 48,62 \\
\hline Controlar recursos materiais & 58,92 \\
\hline Efetuar movimento da tesouraria & 27,99 \\
\hline Efetur serviços referentes a contabilidade & 50,61 \\
\hline Cuidar da gestão contábil & 86,85 \\
\hline CUSTO DAS ATIV. DE APOIO & $\mathbf{2 7 2 , 9 9}$ \\
\hline
\end{tabular}

ATIVIDADES FINS:

\begin{tabular}{|l|r|}
\hline Efetuar empréstimos a pessoa física e jurídica & 116,04 \\
\hline Vender seguros & 196,76 \\
\hline Vender planos de previdência & 33,02 \\
\hline $\begin{array}{l}\text { Vender demais produtos e serviços, orientando } \\
\text { para investimentos }\end{array}$ & 436,44 \\
\hline Efetuar serviços referentes as cobranças & 9,90 \\
\hline Efetuar serviços relativos ao câmbio & 86,39 \\
\hline CUSTO DAS ATIVIDADES FINS & $\mathbf{8 7 8 , 5 5}$ \\
\hline
\end{tabular}

\begin{tabular}{|l|r|}
\hline CUSTO DOS OBJETOS DE CUSTOS & $2.796,90$ \\
\hline TOTAL GERAL DOS CUSTOS & $\mathbf{3 . 9 4 8 , 4 4}$ \\
\hline
\end{tabular}

nários em cada setor e a determinação dos objetos de custos da agência, podem ser simuladas, periodicamente, para se observar o resultado final, em função das transformações. O reflexo será no processo e poderá subsidiar, antecipadamente, as tomadas de decisões.

\subsubsection{Listar ações para melhorias no processo}

As ações listadas para melhoria no processo serão um processo seguinte ao processo anterior, podendo ser, por exemplo, uma nova alocação de pessoal ou uma nova lista de atividade para determinado setor.

\subsubsection{Etapas de avaliação da metodologia}

A princípio, a nova metodologia mostrou-se bastante útil à gerência. No entanto, sabe-se que seu uso necessitará, com o passar do tempo, de cuidados com a aferição dos cálculos realizados e com sua própria importância, a qual poderá cair em função de transformações no fluxograma do processo da agência. Essas avaliações somente poderão ser feitas alguns meses após a implantação.

\subsubsection{Etapas de implementação de melhoria na metodologia}

A avaliação contínua da metodologia levará à necessidade dos ajustes do software e também da implementação de ações de aperfeiçoamento na metodologia. Tendo em vista a preocupação com a continuidade do uso da metodologia do $A B C$, é necessário assegurar o seu progresso continuado e seus benefícios também.

\section{Considerações finais}

A necessidade de se obter a visão de processo, além da funcional, é presente nas agências bancárias, pois estas, como qualquer empresa de serviços ou industrial, vêm passando por transformações impostas pelo mercado competitivo. Para manterem-se à frente desta realidade, são necessárias novas ferramentas de gestão. Baseando-se nestas premissas, foi proposta uma metodologia de custeio para as atividades bancárias.

Espera-se que a metodologia proposta seja utilizada como um meio para aprimorar a competitividade da agência bancária, dispondo as informações de forma a destacar as oportunidades para redução de custos, identificando quais atividades têm ou não valor agregado para os clientes ou quais são desproporcionalmente custosas. Assim, subsidiará a monitoração do desempenho e tomadas de decisões.

O uso da visão de processo e da nova metodologia propiciou informações relevantes à gestão da agência, pois permite:

- visualizar os processos e atividades da agência;

- mensurar o custos dos processos e atividades, facilitando assim as análises de reestruturação ou intervenção em cada processo da agência.

- simular alterações nos processos e atividades da agência obtendo como resultados as alterações nos respectivos custos, fazendo com que fiquem mais coerentes com seus respectivos benefícios. 
- agregar ao atual modelo de desempenho, os indicadores de custo dos processos.

- embutir a avaliação periódica da metodologia proposta para seu aperfeiçoamento contínuo.

O método ABC espelha os custos das atividades da agência, enquanto que o atual modelo de avaliação de desempenho espelha as metas alcançadas. Ambos se somam e geram uma nova ferramenta de controle das informações financeiras aliadas às não financeiras. Vale destacar que a continuidade da agência está totalmente vinculada ao seu desempenho.

As dificuldades que merecem destaque, encontradas na aplicação da metodologia, foram: a definição dos direcionadores e dos objetos de custos da agência. Isso ocorreu em função da não disponibilidade dos meios de controle dos referidos direcionadores e da ausência de análise sob o ponto de vista dos processos da agência. No entanto, a aplicação da metodologia mostrou-se oportuna e relevante, haja vista o crescente interesse, por parte da gerência, em estudar e avaliar o comportamento de seus custos ao longo do processo da agência.

Um novo sistema de informações e de gerenciamento de custos pode gerar bons resultados, mudando o modo no qual o desempenho é medido dentro da organização como um todo. Caberá ao gestor da agência a continuação e aperfeiçoamento da metodologia proposta por este artigo.

A apresentação das informações às pessoas envolvidas no processo da agência e que, principalmente, são as grandes geradoras dos custos, é fundamental ao sucesso e continuação do sistema. Pois do contrário, todo o trabalho perderia o sentido e ficaria limitado às interpretações e ações de uma única pessoa.

Obteve-se como percepção final deste trabalho que o comprometimento da alta gerência em implantações de novos sistemas é de suma importância. Em todas as etapas, o envolvimento da gerência se faz presente, seja para liberação das informações sigilosas, seja para conhecimento de todas as etapas de implantação ou mesmo para aprendizado com os próprios funcionários.

Conclui-se que a mesma metodologia pode ser adaptada a outras agências e, no entanto, pode não apresentar os mesmos resultados, se o envolvimento não for o mesmo ou maior que o verificado nesta pesquisa-ação.

Finalmente, acredita-se que a organização cresce até onde vai o envolvimento da gerência.

\section{Referências}

ABC/ABM Tutor. Release version 2.0, Mar. 1996. Storage Technology Corporation - RPM Associates. http://www.storteck.com Acesso em: 01 Feb. 1998.

BHARARA, A. e LEE, C. Y. Implementation of an activity-based costing system in a small manufacturing company. International Journal of Production Research, v.34, n.4, p.1109-1130, 1996.

BOISVERT, H. Contabilidade por Atividades. São Paulo: Atlas, 1999.

BRIMSON, J. A. Activity Based Management: reasons to Implement. <http:// www.activitybasedmgmt.com/ Activity_Based_Costing.htm>.Acesso em: 29 Aug. 1999.

COMPTON, T. R. Implementing activity-basedcosting. The CPA Journal, v.66, p.20-27, Mar.1996.

DRUCKER, P. Activity based Management: reasons to Implement. Extraído da internet <http:// www.activitybasedmgmt.com/ Activity_Based_Costing.htm>. Acesso em: 29 Aug. 1999.

GEISHECKER, M.L. Tecnologia melhora o ABC. HSM Management. p.18-22, Nov. 1997.

HORNGREN, C.T. et al. Cost Accounting A Managerial Emphasis. 9.ed. Prentice Hal, 1997.

KAPLAN, R.S., NORTON, D.P. A Estratégia em Ação: Balanced Scorecard. Rio de Janeiro: Campus, 1997.

KAPLAN, R. S. e COOPER, R. Custo e Desempenho: administre seus custos para ser mais competitivo. São Paulo: Futura, 1998.

KAPLAN, R. S. Dos Custos à Performance. HSM Management. n.13, p.6-11, Mar. 1999.

MABBERLEY, J. Activity-Based Costing in Financial Institutions How to support value-based management and manage your resources effectively. 2.ed. Londres: Pitman Publishing, 1998.

PLAYER, S. KEYS, D. E., LACERDA, R. S.de ABM: Lições do Campo de Batalha. São Paulo: Makron Books, 1997. 
REIS, L.F.S.D. Gestão da Excelência na Atividade Bancária. Rio de Janeiro: Qualitymark, 1998.

SHARMAN, P. Activity-based management: a growing practice. CMA Magazine, v.67, n. 2, p.17-22, Mar. 1993.

da SILVA, E. R. S. Custeio baseado em atividades Pesquisa-ação em agência bancária. 2000. Dissertação (Mestrado em Engenharia de Produção) - Departamento de Engenharia de Produção, Universidade Federal de Santa Catarina, Florianópolis.

da SILVA, E. R. S. e BORNIA, A. C. A relevância da gestão de custos no cenário das atividades bancárias no Brasil - um ambiente propício ao sistema ABC. In: ENCONTRO NACIONAL DE ENGENHARIA DE PRODUÇÃO - ENEGEP, 18., 1998, Niterói, RJ. Anais... Niterói: UFF.TEP, 1998. CD-ROM. 